American Journal of Applied Sciences 4 (6): 410-416, 2007

ISSN 1546-9239

(C) 2007 Science Publications

\title{
Effect of Covers and Rainfall on Soil and Water Conservation Using a Tilting Flume Model
}

\author{
Compliew, S., Suwanchai, L. and Krongwieng, N. \\ Faculty of Engineering at Mahasarakham University, Thailand
}

\begin{abstract}
The effect of stone and vegetative covers was evaluated for soil and water conservation in a waterway on salty soils in the Northeast of Thailand. Experiments were conducted on a hydraulic tilting flume under simulated unit flow $\left(120\right.$ and $\left.45 \mathrm{~cm}^{2} \mathrm{~s}^{-1}\right)$, rainfall $(120 \mathrm{~mm} / \mathrm{hr})$ and slope $(0$, $1.2,1.4,1.6,1.8,2.0,2.2,2.4,2.6,2.8$ and 3.0\%) conditions. The depth of soil was maintained at 0.20 $\mathrm{m}$. over a perforated bed to facilitate deep drainage. A comparative study of bare soil, stone cover $(50 \%)$ and vegetative cover $(50 \%)$ is made to evaluate soil loss, deep drainage, Manning's roughness coefficient. The study has revealed that stone cover is more effective than vegetative cover at lower discharge in reducing the flow velocity and thereby soil erosion. Deep drainage has been reduced from lower discharge to higher discharge for all the slopes with cover measures, including bare soil. It is also found that cover measures are necessary beyond $2.6 \%$ bed slope in order to prevent rill erosion in salty soils.
\end{abstract}

Key words: Inflow, runoff, deep drainage, soil erosion, soil and water conservation, covers, elephant grass or vetiver grass

\section{INTRODUCTION}

Soil and water conservation have been well recognized as a basic requirement for enhancing agricultural production, particularly in rain fed areas. Agricultural production from rain fed areas is of utmost importance for developing countries such as Thailand, where rain fed agricultural land would remain more than $50 \%$ of the cultivable geographical area of the country, even after achieving maximum irrigation potential. The soil and water conservation measures are primarily intended to check the velocity of runoff, increase infiltration, prevent soil erosion and improve the soil moisture regime ${ }^{[1-6]}$, resulting in increasing crop growth and productivity.

Generally, a watershed consists of cultivable lands interconnected by watercourses. Rainfall producing runoff is generated from cultivable lands that get merged at different places and passes through waterway at great velocity. This high discharge causes formation of gullies in due course of time. It is comparatively easier to tackle or control runoff generation at the field level due to prevailing laminar flow conditions. On the other hand, greater attention needs to be paid to control of runoff and soil loss in watercourses because of runoff's turbulence in nature. In comparison to fields runoff, control in watercourses leads to better and improved groundwater recharge due to higher hydraulic head. Model measures, which can be implemented by farmers on their own, can be developed for effective control of resource losses of this nature. However, it would take a long time and much effort to do this under field conditions in the limited time period.

Keeping in mind, the above facts, conservation measures can be simulated in a laboratory through a hydraulic tilting flume, which can simulate the natural conditions of a waterway. The flume is a channel of glass, usually supported above the surface of the ground to carry water across a depression ${ }^{[7]}$. The hydraulic tilting flume can be used to study the concentrated flow hydraulics in a simulated waterway conditions by adjusting the channel slope. The flume studies give an insight into the water balance components and erosion hazards in simulated flow conditions ${ }^{[8]}$.

This information is of great importance in developing approaches for reducing erosion and improving upon the deep drainage in waterway. By using the hydraulic tilting flume in the laboratory, the effectiveness of different conservation measures with different slope, different rainfall rate and soil conditions can be studied. In the present paper, representative salty soil of the arid region of the Chi river basin, Northeast of Thailand ${ }^{[9]}$, are considered for the experiment, comparing stone and vegetative cover measures with the bare soil condition. The effectiveness of these

Corresponding Author: Compliew,S., Faculty of Engineering at Mahasarakham University, Thailand 
simple conservation measures could help in adopting the practices in a similar watershed situation. Salty soil conditions represent around $50 \%$ of the total geographical area of the Northeast of Thailand, which needs land treatment for proper vegetative growth.

This study deals with the effects of cover measures for soil and water conservation using a tilting flume by representing a waterway in a watershed. The Applied Political Economy Center of Kasetsart University and Royal project of Thailand in the year of 2002 has researched the efficiency and effectiveness of soil and water conservation using vegetation ${ }^{[10]}$. In their research Elephant grass or Typha Elephantina or Vetiver Grass was used to cover the soils on the high lands and it was found that it can reduce soil erosion from surface soil $^{[11]}$. However, in the present experiment only $50 \%$ cover is used with stone and vegetation: to enhance the efficiency of methods used for improving deep drainage and to reduce the cost of cover. Deep drainage studies have also been initiated.

\section{Experiments}

Principle of hydraulic tilting flume: Open channel flow dynamics can be simplified by applying similitude principles. Two forces, gravitational and inertial, act on flow regimes in any sloppy channel ${ }^{[7,8]}$. Different soil erosion patterns caused by sheets of water depend on the ratio of these two forces. The sediment detachment and transport rates will be greater when kinetic energy is higher.

Hydraulic tilting flume details: The tilting flume used in this study consists of a rectangular frame $(12 \times 1.5 \times 0.3$ m) made up of mild steel sheets having a transparent glass on two sides to view the flow profile in the flume. The entire structure can be tilted through a hydraulic mechanism to generate required slope conditions of up to $3 \%^{[12]}$. In addition, the flume consists of a water circulation system and flow measuring devices (water meter, rectangular weir). A rainfall simulator is constructed by connecting nozzles with water lines, which are above the flume. A schematic diagram showing the hydraulic tilting flume set up is shown in Fig. 1.

The flume has capacity to discharge 0 to $0.037 \mathrm{~m}^{3}$ $\mathrm{s}^{-1}$ on a prepared soil bed with any cover measure. The rainfall simulator has capacity to rainfall rate 0 to 120 $\mathrm{mm} \mathrm{hr}^{-1}$

\section{MATERIALS AND METHODS}

The experiment was planned for three conditions: bare soil, stone cover and vegetative (Elephant grass or
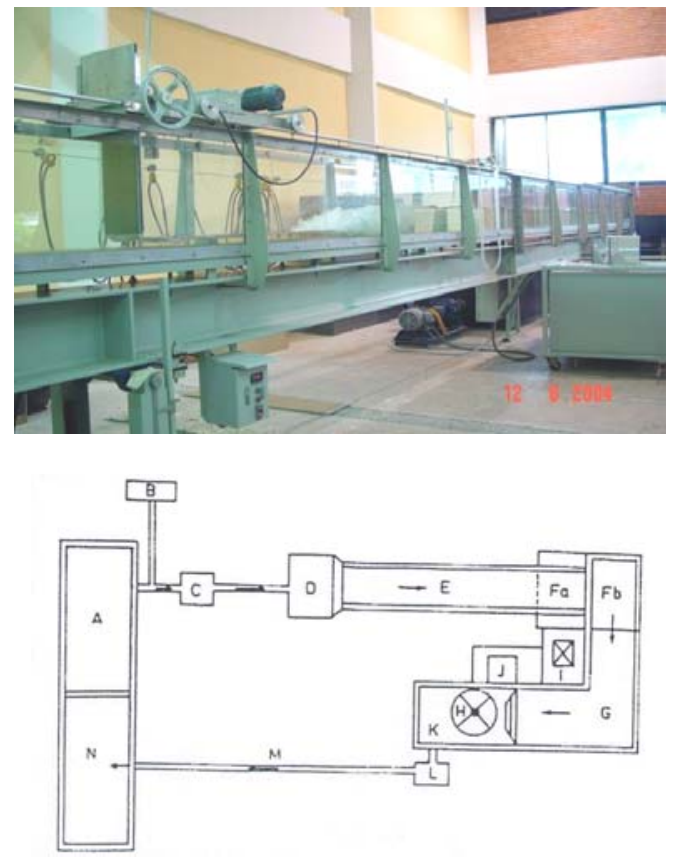

A. Water supply tank

B. Elevated priming tank

C. Pumping unit

D. Stilling trough

E. Tilting flume

Fa. Drainage water

collection tank

$\mathrm{Fb}$. Dead storage stilling tank

G. Runoff channel

H. Coshocton wheel

I. Sediment Sample Collection

J. Stage level recorder

K. Outlet

L. Manhole

M. Return flow line

N. Silt settling tank

Fig. 1: Components of hydraulic tilting flume

Typha Elephantina or Vetiver Grass). Initially the soil bed was prepared throughout the length and breadth of the flume. In this experiment the soil type was salty; the characteristics of the soil are shown in Table 1.

The flume was first filled with soil compacted manually to simulate field conditions. Before each experiment, the soil was saturated and brought to field capacity. Thus the antecedent moisture condition is maintained at field capacity in all the experiments. The effects of cover measures such as stone and vegetative cover in two strips are shown in Fig. 2a and b.

Stones used for this purpose were collected from watershed areas. The average size of stones ranged between 50 and $100 \mathrm{~mm}$. 
Am. J. Appl. Sci., 4 (6): 410-416, 2007

Table 1: Characteristics soil used in tilting flume

\begin{tabular}{ll}
\hline Description & Soil characteristics \\
\hline Soil Type & Salty (Korat and \\
& Roi-et series) \\
Depth & $30 \mathrm{~cm}$ \\
Bulk density & $1.75 \mathrm{~g} \mathrm{~cm}^{-1}$ \\
Sand & $75 \%$ \\
Silt & $15 \%$ \\
Clay & $10 \%$ \\
Textural class & Loamy sand \\
Field capacity & $12.5 \%$ \\
Wilting point & $6.5 \%$ \\
Hydraulic conductivity & $8.2 \mathrm{~cm} \mathrm{~h}^{-1}$ \\
\hline
\end{tabular}

After the stones were arranged on the soil surface, the bed was saturated and the excess water allowed to drain out. Similarly vegetative cover was also prepared on the soil bed using grass (Elephant grass or Typha Elephantina) and was grew 6 months, which is very effective for controlling soil loss (Applied Political Economy Center of Kasetsart University, 2004). On the flume bed the grass strips were planted and the grass was grown in two strips covering $50 \%$ of total area; the height of the grass cover attained $0.20 \mathrm{~m}$. in about 30 days.

In all three cases which consist of bare soil, stone and grass cover. The experiment was run for two different unit discharge $\left(\mathrm{q} 1=45 \mathrm{~cm}^{2} \mathrm{~s}^{-1}\right.$ and $\mathrm{q} 2=120$ $\left.\mathrm{cm}^{2} \mathrm{~s}^{-1}\right)$ and one rainfall rate $\left(120 \mathrm{~mm} \mathrm{hr}^{-1}\right)$. These two discharges and one rainfall rate were repeated for different slopes $(0.2,0.4,0.6,0.8,1.0,1.2,1.4,1.6,1.8$, $2.0,2.2,2.4,2.6,2.8$ and 3.0). Only one run (one discharge one slope one rainfall rate) could be completed in a single day. Before the next run, it was always ensured that the soil brought to field capacity. For each run the measured parameters in the experiment were 1) inflow discharge, 2) flow velocity, 3) outflow discharge, 4) sediment concentration, 5) depth of flow in the flume and the deep drainage. Finally, total runs were generated out of the three treatments, namely, bare soil, stone and grass on 15 slopes with two discharges and one rainfall rate. After that the experimental results in the mean of three replications were used for all calculations and analysis.

\section{RESULTS AND DISCUSSION}

The data were processed to calculate outflow as percent of inflow for all the experiments for various slope categories with respect to bare soil, stone cover and grass cover for two unit discharges $\mathrm{q} 1=45 \mathrm{~cm}^{2} \mathrm{~s}^{-1}$ and $\mathrm{q} 2=120 \mathrm{~cm}^{2} \mathrm{~s}^{-1}$.

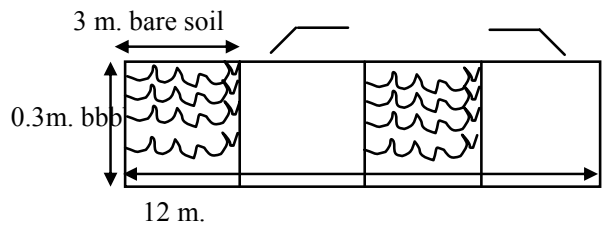

a) Flume bed with $50 \%$ stone cover in two strips of $3 \mathrm{~m}$ length

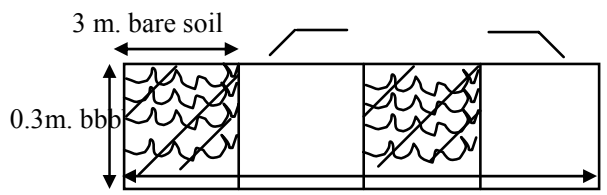

$12 \mathrm{~m}$

b) Flume bed with $50 \%$ grass cover in two strips of $3 \mathrm{~m}$ length

Fig. 2: Flume bed with $50 \%$ covers in two strips of 3 $m$ length

Table 2 show Manning' s roughness coefficient (n), which were calculated for the respective experiments. Using experimental data, graphs are drawn showing slope versus 1) outflow as percent of inflow 2) sediment concentration $\left(\mathrm{kg} \mathrm{m}^{-3}\right)$; 3) flow velocity $\left(\mathrm{ms}^{-1}\right)$ and deep drainage as percent of inflow for various cover measures for both $\mathrm{q} 1$ and $\mathrm{q} 2$ as seen in Fig. 3-6, respectively. All the best fits by regression equations are also shown in the graphs, respectively.

Table 2: Manning's roughness coefficient (n) for different cover measures

\begin{tabular}{lllllll}
\hline $\begin{array}{l}\text { Slope } \\
(\%)\end{array}$ & q1 with rainfall & \multicolumn{3}{c}{ q2 with rainfall } \\
\hline & $\begin{array}{l}\text { Bare } \\
\text { soil }\end{array}$ & $\begin{array}{l}\text { Stone } \\
(50 \%)\end{array}$ & $\begin{array}{l}\text { Grass } \\
(50 \%)\end{array}$ & $\begin{array}{l}\text { Bare } \\
\text { soil }\end{array}$ & $\begin{array}{l}\text { Stone } \\
(50 \%)\end{array}$ & $\begin{array}{l}\text { Grass } \\
(50 \%)\end{array}$ \\
\hline 0.2 & 0.025 & 0.044 & 0.060 & 0.021 & 0.036 & 0.090 \\
0.4 & 0.032 & 0.057 & 0.085 & 0.024 & 0.052 & 0.090 \\
0.6 & 0.039 & 0.068 & 0.110 & 0.027 & 0.068 & 0.090 \\
0.8 & 0.043 & 0.075 & 0.120 & 0.029 & 0.076 & 0.090 \\
1.0 & 0.045 & 0.080 & 0.120 & 0.030 & 0.080 & 0.090 \\
1.2 & 0.045 & 0.082 & 0.115 & 0.030 & 0.080 & 0.089 \\
1.4 & 0.044 & 0.085 & 0.110 & 0.031 & 0.078 & 0.088 \\
1.6 & 0.042 & 0.087 & 0.100 & 0.031 & 0.076 & 0.087 \\
1.8 & 0.041 & 0.088 & 0.090 & 0.031 & 0.072 & 0.086 \\
2.0 & 0.039 & 0.089 & 0.080 & 0.031 & 0.060 & 0.085 \\
2.2 & 0.037 & 0.089 & 0.070 & 0.031 & 0.056 & 0.082 \\
2.4 & 0.033 & 0.089 & 0.060 & 0.031 & 0.052 & 0.082 \\
2.6 & 0.032 & 0.089 & 0.050 & 0.031 & 0.051 & 0.081 \\
2.8 & 0.031 & 0.090 & 0.045 & 0.030 & 0.050 & 0.081 \\
3.0 & 0.030 & 0.090 & 0.040 & 0.030 & 0.050 & 0.080 \\
\hline
\end{tabular}

Effect of slope on outflow: From Fig. 3 it can be observed that in all the cases the outflow as percent of inflow is reduced by the cover measures. Besides, outflow is increased with an increase in slope, almost reaching $100 \%$ for the bare soil at higher slopes and the higher discharge (q2). 
Am. J. Appl. Sci., 4 (6): 410-416, 2007

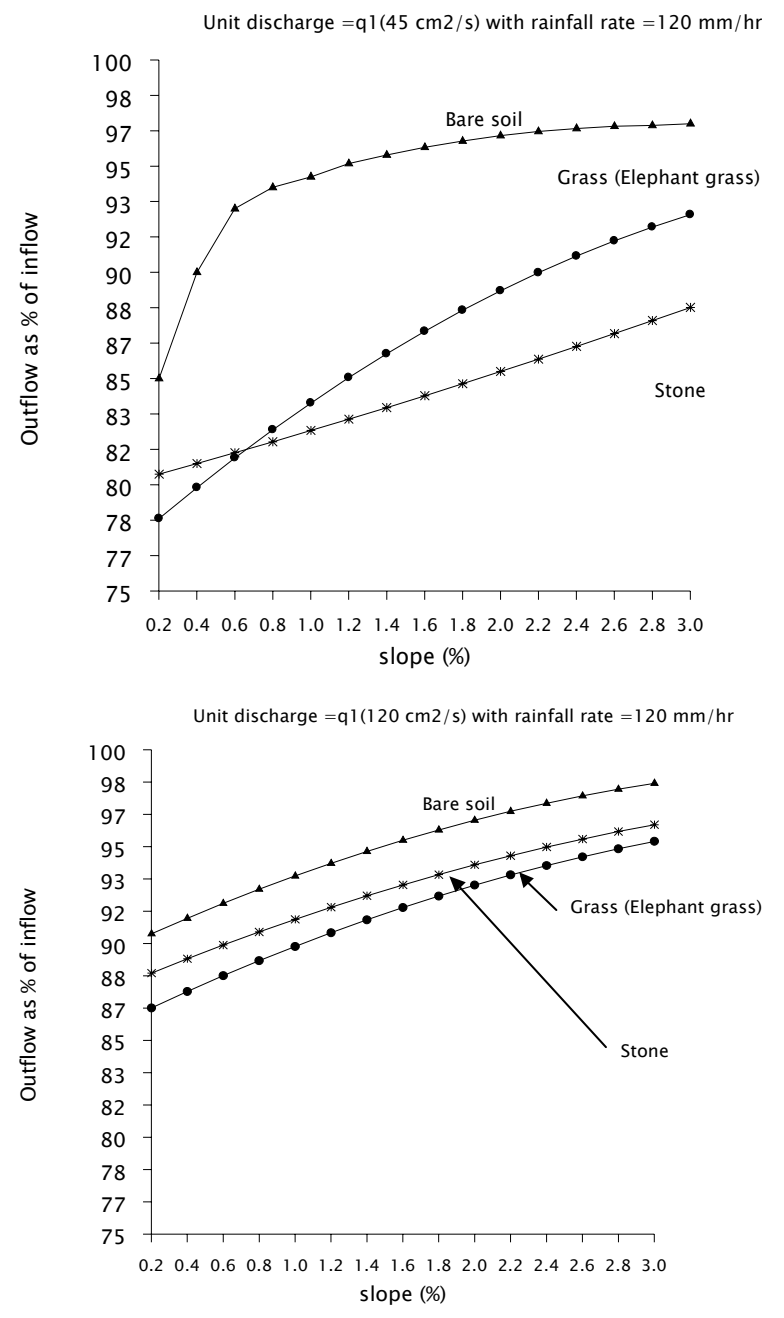

Fig. 3: Relationship between slope and outflow as percent inflow for different covers

The behavior of the relationship between outflow and slope are increased by nonlinear function for the bare soil and Elephant grass cover, but the stone cover is rather increased by linear function for the lower discharge. Elephant grass cover was found to be effective at higher discharge rates when compared to stone and bare soil, as it offers more resistance to flow and confirms in general the observations of previous research. However, the reduction in outflow was effective for the stone cover at a lower discharge rates (q1) for medium slopes (0.6-3\%). This reduction was not as pronounced as at higher discharge rates, wherein Elephant grass cover was effective in reducing the outflow, because the stone cover acts as a true barrier at lower discharge and for higher discharge, the flow is being overtopped.

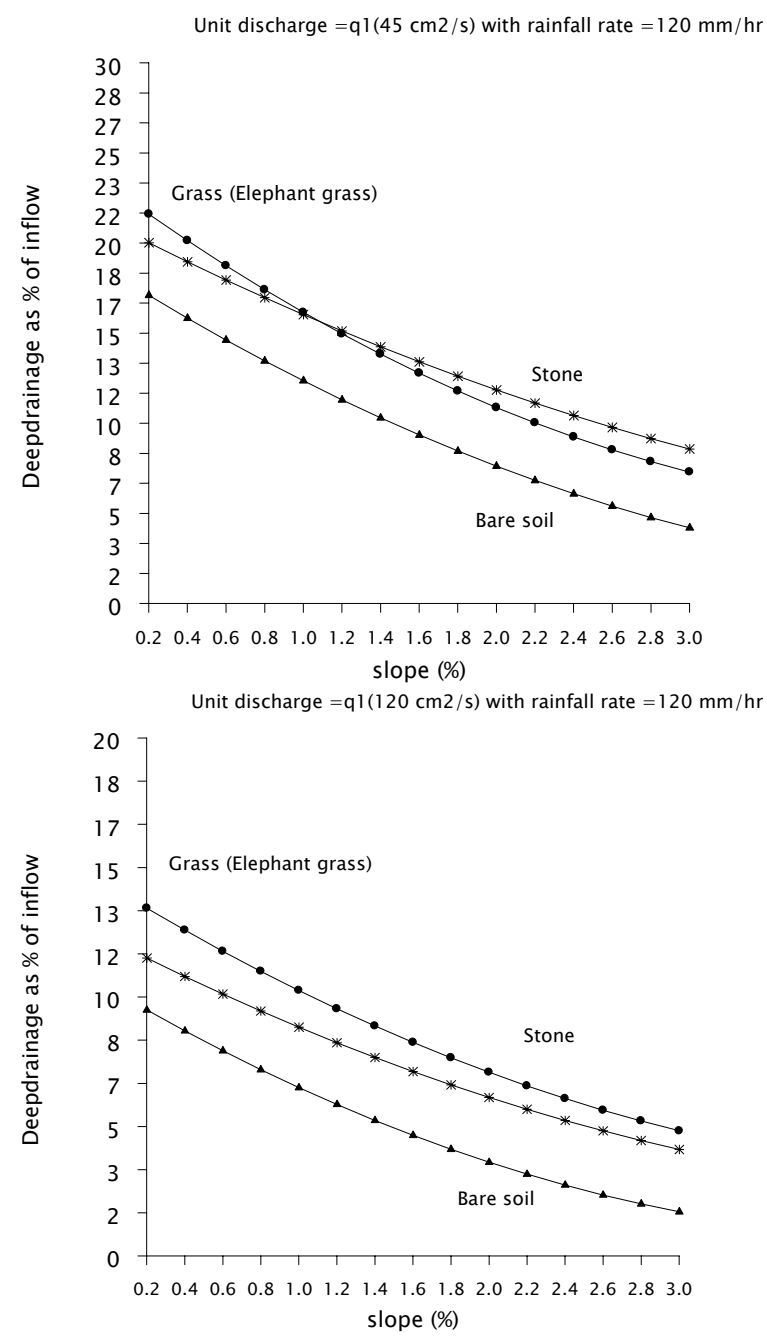

Fig. 4: Relationship between slope and deep drainage as percent inflow for different covers

Effect of slope on Manning's roughness coefficient: Values of Manning's roughness coefficient; $n$ are shown in Table 2. Table 2 shows that the $n$ value is greater for Elephant grass cover for all slopes and both discharges. This indicates that cover measures offer more resistance to the flow. The resistance has diminished with the increase in inflow discharge. This is more pronounced in case of stone cover at higher discharge, as stone strips are submerged and are not acting as barriers. Manning's $n$ has increased up to certain slopes and decreased at higher slopes because the rate of increase of velocity at higher slopes is much higher than lower slopes. 

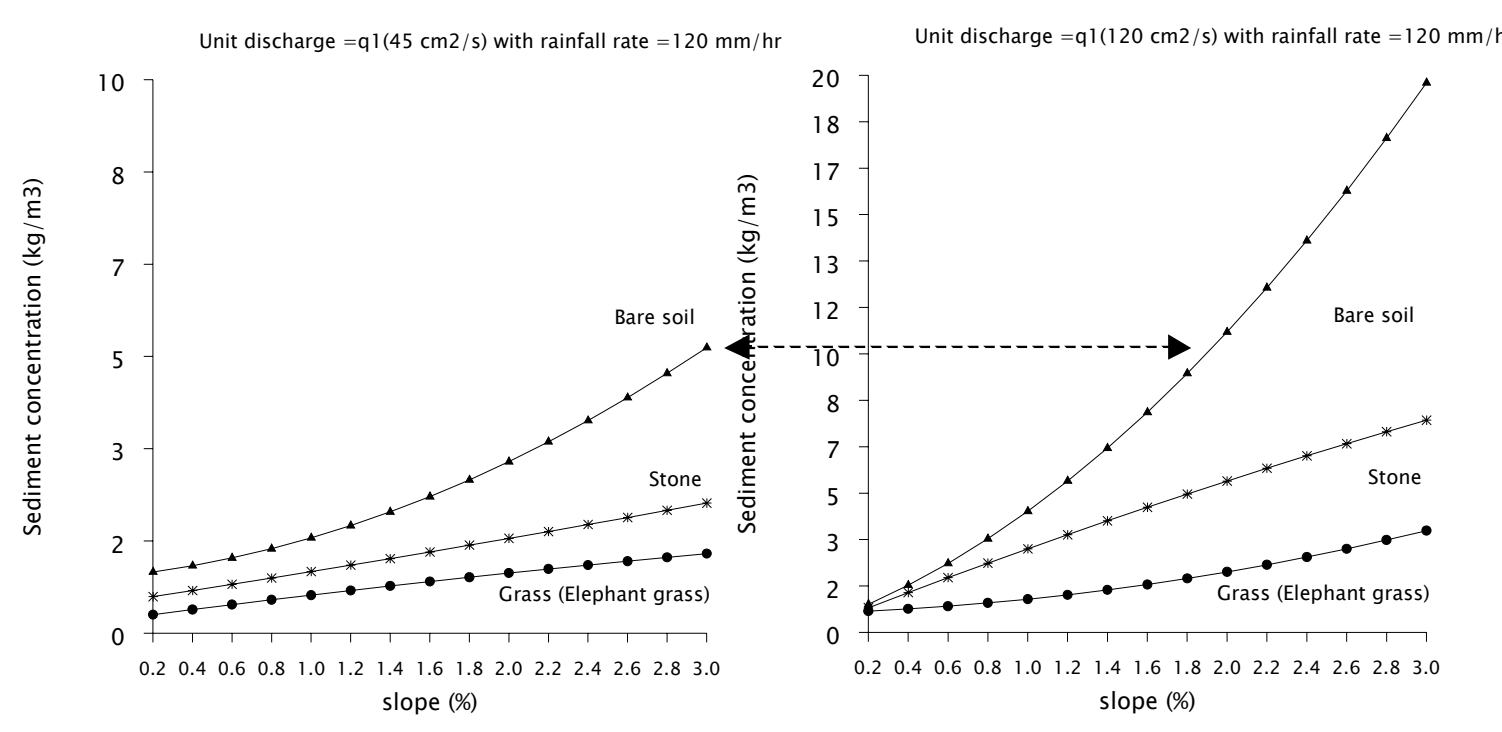

Fig. 5: Relationship between slope and sediment concentration for different covers

Effect of slope on deep drainage: From Fig. 4 the most important point to be noted is that a reduction in deep drainage occurs from the lower to the higher discharge in all the slopes with all the cover measures, including bare soil. This may be explained by considering the contact time with the bed by the lowermost layer of the flow. In the higher, the contact time is less due to the higher velocity, compared to the velocity of flow at the lower discharge. Consequently, opportunity for infiltration becomes less and less as the discharge and velocity increase. The phenomenon is quite clearly understood by considering dynamic and static infiltration. At the lower discharge rate, the deep drainage does not vary with the cover measures, but at a higher discharge rate, Elephant grass has a slight advantage over stone cover in infiltrating more water, though this was less pronounced at higher slopes. This reduced effect at higher slopes may be explained by the fact that the stone cover was making more of an infiltration area than the Elephant grass cover. At higher slopes, this masking effect was less pronounced because of the overall decrease of infiltration as the flow velocity increases. Both lower and higher discharges, the behavior of the relationship between deep drainage and slope are slightly reduced by nonlinear form all three covers.

Effect of slope on sediment concentration: In Fig. 5 it can be observed that the soil loss in terms of sediment concentration $\left(\mathrm{kg} \mathrm{m}^{-3}\right)$ in bare soil was very high for discharge q2 when compared to discharge $\mathrm{q} 1$. Moreover, up to $1 \%$ slope, there was very little effect of discharge as well as cover measures on soil loss. This may be due to the fact the flow velocity was almost non-erosive up to the $1 \%$ slope. At lower discharge, it hardly matters, with respect to soil loss, whether the soil is covered with either Elephant grass or stone in all the slopes, but at higher discharge, Elephant grass is very effective when compared to stone cover. It can be explained that at lower discharge rates, comparing grass and stone cover, Elephant grass offered nearly the same resistance as stone to the flow of water. At higher discharge rates, the stone cover was submerged, whereas the grass cover was erect, protruding above the water surface and offering more resistance to water flow. Another important observation is that rill formation was noticed only at the higher discharge, with 3\% slope for bare soil and more than 3\% slope for all covers, which means that in salty soil, cover measures are necessary beyond 3\% slope in order to prevent rill erosion. The behavior of the relationship between the sediment concentration and slope is rather increased by nonlinear form in bare soil, but both grass and stone covers are slightly increased near by linear form. For the turbulent flow (high discharge) the sediment concentration on bare soil is sharply increased by linear form with near $2 \%$ slope.

Effect of slope on flow velocity: From Fig. 6., it is interesting to note that higher velocities are observed in 
Am. J. Appl. Sci., 4 (6): 410-416, 2007
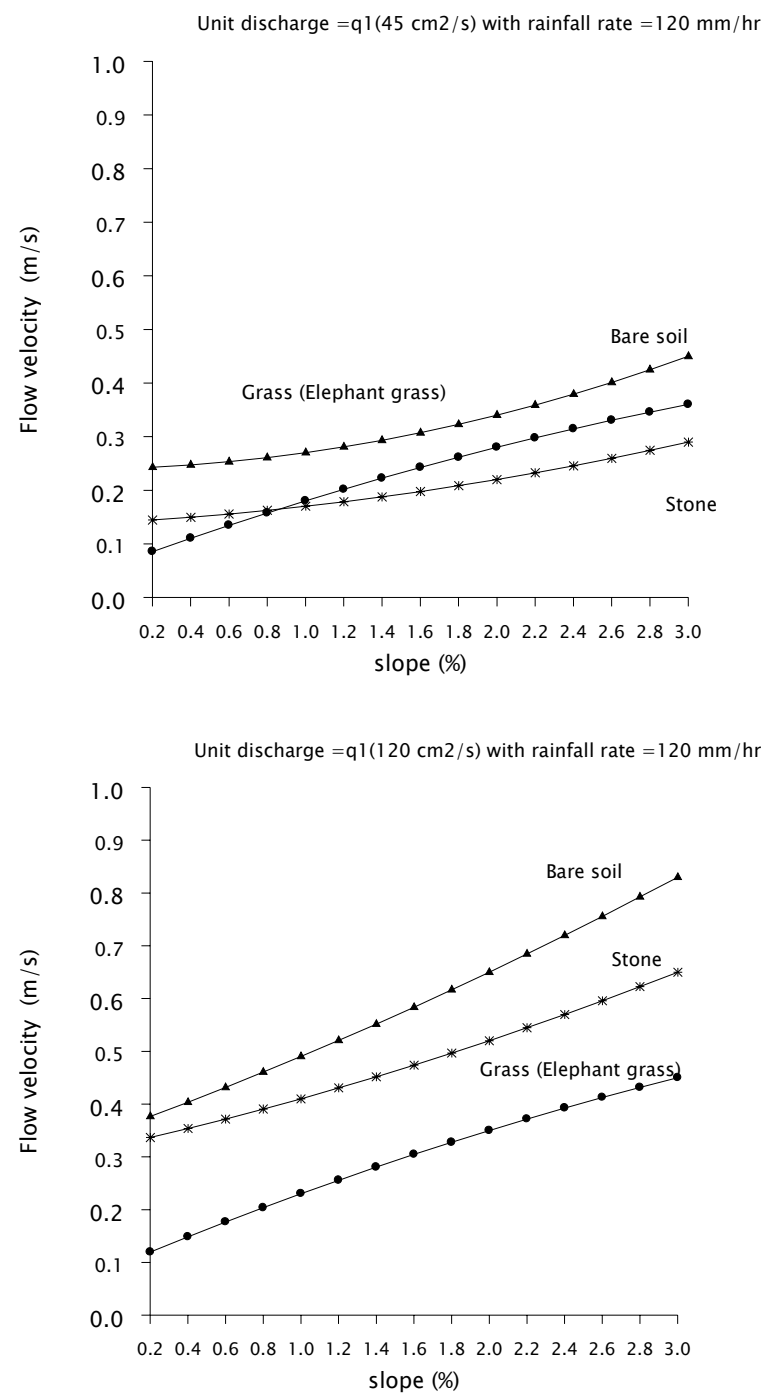

Fig. 6: Relationship between slope and flow velocity for different covers

the case of Elephants grass cover compared to stone cover at lower discharge. This is due to the fact that at lower discharge, stone strips acted like small checks in considerably reducing the flow velocity, while the grass allowed the water to pass with uniform resistance. In the case of cover measures, the rate of increase in velocity was much lower than for the bare condition. From the figures it can be observed that the erosive velocity was obtained at $1,1.7$ and $2.5 \%$ slopes in the case of bare soil, soil with stone cover and soil with Elephant grass cover, respectively, for discharge q1. For discharge q2, both bare soil and stone cover exceeded the erosive velocity at $0.2 \%$ slope itself, whereas for Elephant grass cover the erosive velocity was obtained at range about 1.2-1.5 \%slope. The behavior of the relationship between flow velocity and slope are increased near by linear form for the turbulent flow.

\section{CONCLUSION}

In many places in the Northeast of Thailand, the terrain is covered with stones of varying sizes. Stone cover is the cheapest mode of cover, which is readily available in situ and needs no maintenance. Moreover, it is observed from the result discussion that stone cover is more effective than Elephant grass cover at lower discharges (laminar flow) in reducing flow velocity and soil erosion. Another point is that while preventing soil loss, stone cover is 4 to 5 times more effective than bare soil, but Elephant grass is the most effective if properly established. In cases where grass or vegetative covers cannot be properly established in ephemeral streams of arid and semiarid regions, stone cover may be useful in reducing soil loss and increasing deep drainage for groundwater recharge. These covers are needed where erosive velocity is anticipated for higher peak flows (turbulent flow). In order to prevent rill erosion, cover measures beyond a $2.6 \%$ slope are essential. Manning 's roughness coefficient increases with cover measures from bare soil to stone cover and then to Elephant grass cover, which is an indication of cover measures offering more resistance to flow of water. In the earlier study, soil and water conservation measures usually study in situ, for this experiment tend to see the behavior of the relationship between parameters (outflow, sediment concentration, deep drainage and velocity of flow) and slope under the minimum cost of covers by considering the effect of rainfall, only $50 \%$ of covers can be given the effective of soil and water conservation. The effects of these parameters which are available data that can be applied for soil and water conservation measures management in field.

\section{ACKNOWLEDGEMENTS}

During research study, the budgets was gotten from the budgets fund of Mahasarakham University of Thailand in 2005. The goodness that can be gotten from this paper, to indebted to the everybody to support and their willpower.

\section{REFERENCES}

1. Dabney, W.C., L.D. Meyer, W.C. Harman., C.V.D. Alomo and G.R. Foster, 1995. Depositional patterns of sediment trapped by grass hedges. Trans. ASCE, 38: 1719-1729. 
2. Ghadiri, H., C.W. Rose and W.L. Hogarth, 2001. The influence of grass and porous strips on runoff hydrology and sediment transport. Trans. ASCE, 44: 259-268.

3. Juyal, G.P. and G. Shastry, 1991. Erosion losses and process studied for spurs for stream bank erosion control. Annual Rep. 1990-1991, Central Soil and Water Conservation Research and Training Institute (CSWCRTI), Dehradun, India, pp: 88-90.

4. Meyer, L.D., S.M. Dabney and W.C. Harmon, 1995. Sediment- trapping effectiveness of stiff grass hedges. Trans. ASAE, 38: 809-815.

5. Morgan, R.P.C. and R.J. Rickson, 1995. Slope stabilization and erosion control: A bio-engineering approach. E\&FN Spon, London, pp: 133-179.

6. Panigrahi, D., N. Sahoo and G. Patnaik, 1999. Entrainment ratio of clay soil in overland flow. Indian J. Soil Conservation, 27: 193-197.

7. Chow, V.T., 1981. Open channel hydraulics. McGraw-Hill, New York, pp: 13-78
8. Sharp, J.J., 1981. Hydraulic Modelling. Butterworth \& Co (Publishers) Ltd., London, pp: 1- 242.

9. Pamornchan, B. and J. Krisanamara, 1989. The research for soil and water conservation in the Northeast Region of Thailand. Proceeding on Research and Development strategies on soil and water conservation in the Northeast, Agriculture development research center in the northeast ,Thailand., Khon Kaen province and office of the permanent secretary ministry of Agriculture , Sep.13-16.

10. The Applied Political Economy Center of Kasetsart University and Royal project of Thailand, 2002. Royal Project in the highland. Draft Final Report.

11. Diti, H., 2000. Vetiver Grass for Slope Stabilization and Erosion Control", PRVN Technical Bulletin No 2/1998.

12. Essom Co; Ltd., 1985. Transparent sided tilting flume manual. 